\title{
Biodegradation of Toxic Compounds in Olive Mill Wastewater by a Newly Isolated Potent Strain: Aspergillus niger van Tieghem
}

\author{
Fatiha Hanafi $^{1 *}$, Mohammed Mountadar ${ }^{2}$, Samira Etahiri ${ }^{1}$, Mohamed Fekhaoui ${ }^{3}$, Omar Assobhei ${ }^{1}$ \\ ${ }^{1}$ Laboratoire de Biotechnologies Marine et de l’Environnement, Faculté des Sciences, Université Chouaib Doukkali, \\ El Jadida, Morocco \\ ${ }^{2}$ Unité de Chimie Analytique et Sciences de l’Environnement, Faculté des Sciences, Université Chouaib Doukkali, \\ El Jadida, Morocco \\ ${ }^{3}$ Département de Zoologie et Ecologie Animale, Institut Scientifique, Université Mohammed V-Agdal, \\ Rabat, Morocco \\ Email: *hanafifatiha@yahoo.fr
}

Received May 22, 2013; revised June 3, 2013; accepted August 4, 2013

Copyright (C) 2013 Fatiha Hanafi et al. This is an open access article distributed under the Creative Commons Attribution License, which permits unrestricted use, distribution, and reproduction in any medium, provided the original work is properly cited.

\begin{abstract}
Thirty-two strains isolated from olive oil production plants were screened for their tolerance to the polyphenols and their ability to grow in olive oil mill wastewaters (OMW). An Ascomycete isolate that grew best on OMW was selected for further study to evaluate its effect on removal of organic pollutants, phenolic compounds and OMW toxicity. This strain was identified by DSMZ as Aspergillus niger van Tieghem. The growth of Aspergillus niger van Tieghem on stored OMW decreased pH and led to the reduction of phenolic compounds with a resultant discoloration of OMW and significant reduction of chemical oxygen demand (COD), in proportion to the dilution of OMW. The reduction of the COD, phenolics and color exceeded 50\%. Tannase, the enzyme detected in the growth medium of Aspergillus niger van Tieghem was produced during primary metabolic growth. The maximal enzyme activity attaining $0.68 \mathrm{EU} / \mathrm{ml}$ was achieved in 3rd days of cultivation. The phytotoxicity of the stored OMW was reduced to about $40 \%$ after 4 days' incubation with Aspergillus niger van Tieghem.
\end{abstract}

Keywords: Aspergillus niger van Tieghem; Olive Oil Mill Wastewaters; Phenolic Compounds; Tannase; Toxicity

\section{Introduction}

Over 750 million olive trees are cultivated worldwide, $95 \%$ of which are in the Mediterranean region. The olive oil industry produces $440 \mathrm{~L}$ oil mill wastewater per 100 $\mathrm{kg}$ of treated olive [1]. Olive mill wastewaters (OMW) are dark liquid effluents, which pose a critical problem for olive oil producing countries. They have a very high organic load, chemical oxygen demand (COD) generally varying from 50 to $200 \mathrm{~g} / \mathrm{l}$. These values are 200 to 400 times higher than municipal water [2]. The major components in the colored fraction are substances of polymeric nature, derived from several low molecular weight phenolic compounds, chemically related to lignin and humic acids [3]. OMW phytotoxicity is essentially linked to its high phenolic compounds content that are the modified forms of phenols of the olive fruit [4]. Because of its

\footnotetext{
*Corresponding author.
}

special characteristics, OMW treatment and valorization are serious problems for Mediterranean countries producing annually around $30 \mathrm{million} \cdot \mathrm{m}^{3}$ of OMW [4]. Many processes have been developed to treat this effluent: The currently employed systems for OMW treatment can be classified as biological, physicochemical, or combined processes. Various physico-chemical methods have been proposed for treating OMW, including simple evaporation, electrocoagulation [5], oxidation by ozone and Fenton reagent [6], as well as reuse of the OMW by spreading onto agricultural soil as an organic fertilizer [4]. The use of microorganisms to remediate contaminated sites or break down toxic effluent wastes is gaining wide acceptance and practice. Biodegradation is versatile, inexpensive, and can potentially turn a toxic material into harmless end-products. Because toxicity has been directly linked to the phenolic fraction, higher fungi such as Yarrowia lipolytica [7] and Paecilomyces farinosus [8] have 
been proposed to detoxify and de-colorize the OMW. However, most of previous studies regarding the screening of fungi for biotechnological purposes have focused on species or strains deposited in culture collections [9]. Therefore, it may be beneficial to investigate new fungal isolates for potential applications in the field of bioremediation.

The present work was aimed at studying the ability of an Ascomycete, newly isolated from olive oil production plants and classified as Aspergillus niger van Tieghem (DSM 24787), to modify the polluting properties and reduce the phytotoxicity of OMW in comparison with that of Phanerochaete chrysosporium Burdsall M1 [10].

\section{Materials and Methods}

Olive mill wastewater (OMW) was collected from an olive oil factory in Marrakech (Morocco), and stored at $4^{\circ} \mathrm{C}$ until use. The samples used in the experiments were filtered through cotton to remove suspended particles. The effluent characteristics, in terms of COD, phenolic compounds and color, were $114 \mathrm{~g} \mathrm{O}_{2} / \mathrm{l}, 18 \mathrm{~g} / \mathrm{l}$ and 16 (absorbance at $\lambda=395 \mathrm{~nm}$ ), respectively.

\subsection{Strain and Cultures Conditions}

Two different fungal strains were used in the OMW treatment experiments: a strain isolated from olive oil production plants using the agar plate technique and classified by DSMZ (Braunschweig, Germany) as Aspergillus niger van Tieghem (DSM 24787) and Phanerochaete chrysosporium Burdsall M1 (DSM 13583) [10] isolated from OMW. Fungi were maintained through periodic transfer at $4^{\circ} \mathrm{C}$ on potato-dextrose (2.4\%) agar plates in the presence of $0.5 \%$ yeast extract.

\subsection{Solid Cultures}

Cultures on solid media were conducted in duplicate, in plates containing $10 \mathrm{ml}$ of a sterile solution composed of potato-dextrose agar and OMW.

\subsection{Inocula Preparation}

Before using in the biodegradation experiments, the strains were first precultivated during 2 days for $A$. niger and 5 days for $P$. chrysosporium at $28^{\circ} \mathrm{C}$ under agitation (rotary shaker-150 rpm) in $50 \mathrm{ml}$ of the liquid version of OMW-based medium supplemented with $0.35 \%\left(\mathrm{NH}_{4}\right)_{2} \mathrm{SO}_{4}$ and $0.065 \% \mathrm{KH}_{2} \mathrm{PO}_{4}(\mathrm{w} / \mathrm{v})$, contained in $250 \mathrm{ml}$ Erlenmeyer flasks.

\subsection{Liquid Cultures}

Liquid cultures were conducted in duplicate, in $250 \mathrm{ml}$ Erlenmeyer flasks containing $50 \mathrm{ml}$ of an OMW (25\%, $50 \%, 75 \%$ and $100 \%(\mathrm{v} / \mathrm{v})$ ) sterile supplemented uni- formly with $0.35 \%\left(\mathrm{NH}_{4}\right)_{2} \mathrm{SO}_{4}$ and $0.065 \% \quad \mathrm{KH}_{2} \mathrm{PO}_{4}$ $(\mathrm{w} / \mathrm{v})$, and adjusted to the final volume with tap water. The flasks were inoculated with $0.4 \mathrm{~g} / \mathrm{l}$ dry weight fungal biomass and incubated in a rotary shaker at $150 \mathrm{rpm}$ and $28^{\circ} \mathrm{C}$. Samples were taken daily for analysis.

\subsection{Biomass Estimation}

Biomass produced during cultivation of $A$. niger and $P$. chrysosporium on the OMW media was estimated by filtration of the culture medium on glass microfibres (GF/A Whatman Inc.). The retained biomass was washed twice with $5 \mathrm{ml}$ distilled water and dried overnight at $105^{\circ} \mathrm{C}$. Growth yield was expressed as gram of dry weight per liter of culture.

\subsection{Estimation of Tannase Activity}

Tannase was estimated by the spectrophotometric assay of Aissam et al. [11]. One unit of enzyme activity (EU) was defined as the amount of enzyme catalyzing the hydrolysis of one $\mu$ mol tannic acid per minute. The results are expressed in $\mathrm{EU} / \mathrm{ml}$.

\subsection{Analytical Methods}

Before analysis the samples were filtred on glass microfibres [GF/A Whatman Inc.). In the sample, COD, polyphenols, dark color intensity and $\mathrm{pH}$ were measured. Chemical oxygen demand (COD) were determined according to APHA standards methods [12].The dark color intensity was determined by measuring the sample's absorbance at $395 \mathrm{~nm}$ respectively using a CARY 1E VA RIAN spectrophotometer, in 1cm path-length cells [13]. Determination of the concentration of total polyphenols was carried out with the official spectrophotometric procedure $(720 \mathrm{~nm})$ in which the reagent Folin-Ciocalteu was used as a selective reagent for polyphenols [14] using a CARY 1E VARIAN spectrophotometer, the results were expressed as gram of gallic acid per liter. OMW phytotoxicity was quantitatively estimated using the parameter of "Germination Index" (G.I.) as described by Komilis et al. [15]. Assays were performed using Triticum sativum seeds.

\section{Results and Discussion}

\subsection{Isolation and Identification Studies}

It is well known that OMW contains all essential elements for microbial growth (e.g. carbon and nitrogen sources, minerals), but also several growth inhibitors, such as organic acids and phenolic compounds. 32 strains isolated from pomace or OMW were screened for their tolerance to the polyphenols and their OMW-decolorizing potential on potato dextrose agarsupplemented with OMW (Table 1). Radial growth was measured daily. 
Table 1. Comparative radial growth in PDA supplemented with OMW of 32 fungi after 3 days of incubation (HF 25 = Aspergillus niger van Tieghem).

\begin{tabular}{|c|c|}
\hline Strains & Radial growth $(\mathrm{cm})$ \\
\hline P. chrysosporium & 4 \\
\hline HF1 & 1 \\
\hline HF2 & 4 \\
\hline HF3 & 1 \\
\hline HF4 & - \\
\hline HF5 & - \\
\hline HF6 & - \\
\hline HF7 & 1 \\
\hline HF8 & - \\
\hline HF9 & 1.75 \\
\hline HF10 & - \\
\hline HF11 & - \\
\hline HF12 & - \\
\hline HF13 & 1.5 \\
\hline HF14 & 1.12 \\
\hline HF15 & 1.5 \\
\hline HF16 & 2.5 \\
\hline HF17 & 3.98 \\
\hline HF18 & 2.5 \\
\hline HF19 & - \\
\hline HF20 & 2 \\
\hline HF21 & - \\
\hline HF22 & 1 \\
\hline HF23 & 2.75 \\
\hline HF24 & - \\
\hline HF25 & 4 (after 2 days) \\
\hline HF26 & 2.5 \\
\hline HF27 & 1.5 \\
\hline HF28 & 3 \\
\hline HF29 & 2.2 \\
\hline HF30 & 2.4 \\
\hline HF31 & 2.85 \\
\hline HF32 & 3.98 \\
\hline
\end{tabular}

Strain HF25 showed colonies reaching $9 \mathrm{~cm}$ (the maximum) in diameter in 2 days at $28^{\circ} \mathrm{C}$ whereas $P$. chrysosporium reached the same value after 3 days. During strain HF25 growth a discoloration of the medium progressively occurred in the plates. Discoloration began with the formation of clear zones around the colonies.
Complete discoloration was assessed as the total disappearance of color without any visible sorption to the biomass. These tests showed that strain HF25 had the best capability of removing black color and was further identified by DSMZ as Aspergillus niger van Tieghem (DSM 24787) on the basis of morphology. This strain had a conidiophores thick-and smooth-walled, up to 15 $\mu \mathrm{m} \varnothing$, terminating in globose vesicles of mostly 40 - 50 (-60) $\mu \mathrm{m} \varnothing$. Metulae mostly present in larger conidiophores up to $12 \mu \mathrm{m}$ long; phialides ampulliform, 7 - 8 $\mu \mathrm{m}$ long, with a short neck; conidia more or less globose, mostly 4 - $4.5 \mu \mathrm{m} \varnothing$, brown, surface ornamented with warts. According to these preliminary results, all the following trials were performed with Aspergillus niger van Tieghem strain in sterile media.

\subsection{Effect of Initial COD on OMW Treatment}

Table 2 shows the physicochemical characteristics changes in OMW after 7 days incubation with strains of Aspergillus niger van Tieghem in shaken culture. Results indicate that a direct effect of initial OMW concentration on COD, total phenolic compounds (PC) and phytotoxicity removals was observed. For the medium containing $\mathrm{COD}_{0}=28 \mathrm{~g} / \mathrm{l}$ and $\mathrm{COD}_{0}=57 \mathrm{~g} / \mathrm{l}$ the percentage of total phenolic compounds removal was ranged between 56\% and $45 \%$ respectively. The percentage of COD removal was ranged between $63 \%$ and $53 \%$ respectively. Whereas the reduction of phytotoxicity was $39 \%$ for $\mathrm{COD}_{0}=28$ $\mathrm{g} / \mathrm{l}$ and $10 \%$ for $\mathrm{COD}_{0}=57 \mathrm{~g} / \mathrm{l}$. For the medium containing OMW with $\mathrm{COD}_{0}=85 \mathrm{~g} / \mathrm{l}$ and $\mathrm{COD}_{0}=114 \mathrm{~g} / \mathrm{l}$ no significant growth in term of biomass increase was observed. Phenolic components, when present above a

Table 2. pH, biomass concentrations and removal percentage of COD, phenolic compounds (PC), color and phytotoxicity of $\mathrm{OMW}$ incubated 7 days with $A$. niger.

\begin{tabular}{|c|c|c|c|c|}
\hline Initial COD (g/l) & 28.5 & 57 & 85.5 & 114 \\
\hline COD reduction (\%) & 63 & 61 & 6 & 0 \\
\hline Initial PC (g/l) & 4.5 & 9 & 13.5 & 18 \\
\hline PC reduction (\%) & 56 & 55 & 0 & 0 \\
\hline $\begin{array}{c}\text { Initial color } \\
(\text { Abs } 395 \mathrm{~nm} \times 100)\end{array}$ & 16 & 32 & 48 & 64 \\
\hline Color reduction (\%) & 25 & 14 & 0 & 0 \\
\hline Initial $\mathrm{pH}$ & 4.68 & 4.61 & 4.59 & 4.57 \\
\hline Final $\mathrm{pH}$ & 6.23 & 5.75 & 4.49 & 4.48 \\
\hline Initial phytotoxicity (\%) & 100 & 100 & 100 & 100 \\
\hline phytotoxicity reduction (\%) & 39 & 10 & 0 & 0 \\
\hline Generated biomass (mg) & 240 & 330 & $\begin{array}{c}\text { No } \\
\text { growth }\end{array}$ & $\begin{array}{c}\text { No } \\
\text { growth }\end{array}$ \\
\hline
\end{tabular}


critical concentration, were identified as key factors conditioning OMW toxicity towards microorganisms and plants [14]. Various mechanisms may explain the toxicity of phenolic components, depending in part of the polymerisation degree of the fraction. Polyphenols, including tannins affect the integrity of cell membrane [16]. Lower molecular weight fractions of phenolics, able to cross cell membrane, can provoke a general protein denaturation effect. Moreover, some phenolics were shown to initiate radical reactions leading to harmful reactive oxygen species [17].

\subsection{Biodegradation of OMW with Aspergillus niger van Tieghem}

The potential of the chosen strain of Aspergillus niger van Tieghem to biologically treat OMW was tested in shaken culture. Total phenolic removal, COD removal and generated biomass were monitored with respect to time (Figure 1). Total phenolic and COD removals started on the $2^{\text {nd }}$ day of incubation. Maximum total phenolic and COD removal determined at the end of the incubation

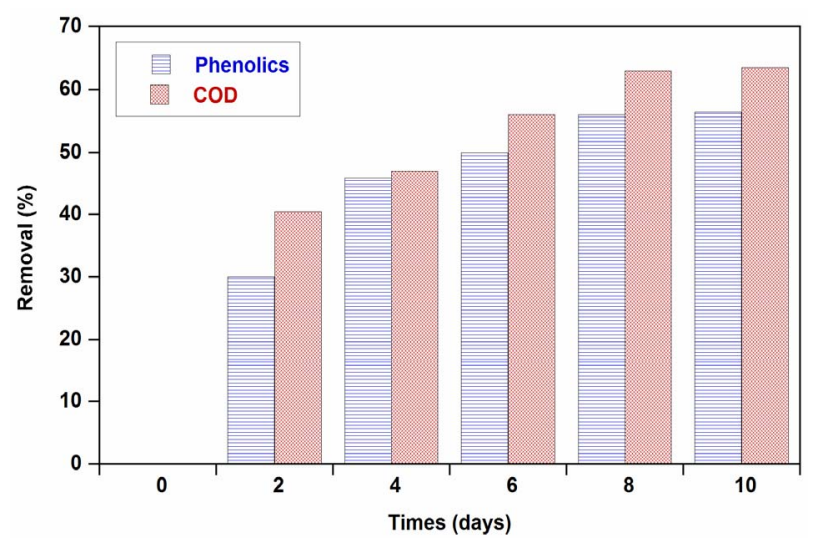

Figure 1. Time course of phenolics and COD removal and generated biomass in OMW treated with $A$. niger.

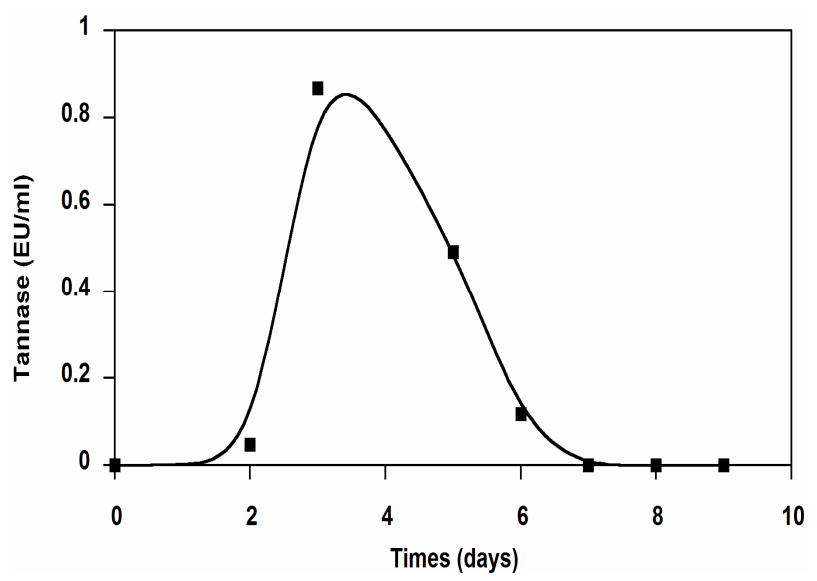

Figure 2. Tannase activity produced by $A$. niger growing OMW. period were $56 \%$ and $63 \%$, respectively and was accompanied by a biomass production of $240 \mathrm{mg}$ dry weight. Hamdi et al. [18] reported that after $72 \mathrm{~h}$, the COD removal rate determined on OMW filtrate fermented by $A$. niger was $61.6 \%$ in flasks and $52.5 \%$ in the fermentor. Ongen et al. [13] reported that $A$. tubingensis Ege-K 265 was able to remove $26.35 \%$ of the phenolic compounds in two-fold-diluted OMW medium within $48 \mathrm{~h}$, while $29.13 \%$ of phenolic compounds were removed from the undiluted medium within $48 \mathrm{~h}$. At the same time, total phenolic removals were correlated with tannase production (Figure 2). The maximum tannase production reached to 0.867 $\mathrm{EU} / \mathrm{ml}$ on the $3^{\text {rd }}$ day of incubation. This may prove that the enzymatic system of these fungi was well involved in the organic compounds degradation. The results of analysis of tannin-like compounds from OMW before and after culture of $A$. niger in Erlenmeyer flasks showed that the efficiency of the degradation of simple phenolic compounds by this fungus was $55.5 \%$; this efficiency was 73.5\% for hydrolysable tannins [18].

Furthermore, tannase production by A. niger HA37 on four-fold diluted OMW as substrate, was between 0.37 and $0.65 \mathrm{EU} / \mathrm{ml}$ and it was correlated with about $70 \%$ degradation of phenolic compounds present in the OMW [11]. The production of tannase increased with the initial concentration of the tannic acid as substrate: maximal enzyme activities attaining $0.6,0.9$ and $1.5 \mathrm{EU} / \mathrm{ml}$ in the culture medium containing, respectively, $0.2 \%, 0.5 \%$ and $1 \%$ tannic acid. This suggests that the concentration of theinducing fraction derived from tannic acid (possibly gallic acid or a derivative) increased according the initial concentration of the substrate [8]. These results suggest that tannins and phenolic compounds present in OMW induce the production of tannase. Ayed and Hamdi [19] reported that stored black OMW showed one family of aromatics formed by polyphenols with high molecular weight. This family was responsible for the dark color. They showed also that the growth of Lactobacillus plantarum (tannase producing) on stored black OMW induced the depolymerization of dark phenolic compounds with high molecular weights into lower molecular weights, more biodegradable. These results suggest that tannase may be the major system responsible for the deploymerization and subsequent of discoloration of this effluxent.

The coloration of OMW decreased markedly after 2 days cultivation with the strains $A$. niger. OMW discoloration occurred during the primary phase of growth because of rapid production of tannase. The color reduction was $64 \%$ and it changed from black to light brown. A slight darkening of the mycelia pellets was also observed. The discoloration was probably due to the degradation and adsorption of some phenolic compounds on the fungal mycelium, these results were already shown by Ongen $e t$ 
al. [13]. This adsorption may be due to the hydrogen bound between phenolic compounds and proteins or to the chitin of the mycelial wall, which has a strongly coagulant effect [11]. At the end of the incubation (6 - 10 days), the color removal rate appeared to decline. The initial $\mathrm{pH}$ values in cultures were experimentally of 4.68 . The $\mathrm{pH}$ values decreased to 2.5 on the $2^{\text {nd }}$ day of incubation. This was most likely a result of the activity of $A$. niger. Indeed, previous works showed that this fungus is known for the production of acid metabolite products [20]. At the end of treatment the $\mathrm{pH}$ values was 6.23 . The observed $\mathrm{pH}$ increase was due to the consumption of organic acids such as lactic and acetic acids present in the OMW [21]. Discoloration was also improved by the low $\mathrm{pH}$ obtained at the beginning of the culture. A significant correlation between discoloration and $\mathrm{pH}$ profiles was observed (Figure 3). In fact, Qin et al. [22] noticed that the color of green tea catechins changed from light brown to dark brown with $\mathrm{pH}$ increases. Moreover, they are more stable and not oxidized in acid solutions. In fact, when the $\mathrm{pH}$ exceeds 6 , phenolic compounds polymerize and give dark polymers [23], which adsorb strongly to proteins. Dif- ferent mecha- nisms are possible for OMW decolorisation. Presumably, the degradation and adsorption of some phenolic com- pounds on the fungal mycelium, deploymerization of dark phenolic compounds with high molecular weights into lower molecular weights, and acidic $\mathrm{pH}(<4)$ may be the major system responsible for discoloration of this effluent.

\subsection{Comparison of $A$. niger and $P$. chrysosporium Degrading OMW}

Phanerochaete chrysosporium Burdsall M1 (DSM 13583) [10] strain was isolated from OMW. Our studies consist to compare the performance of both of strains: A. niger and $P$. chrysosporium for their ability to biodegrade products in OMW. Experiments with P. chrysosporium Burdsall M1

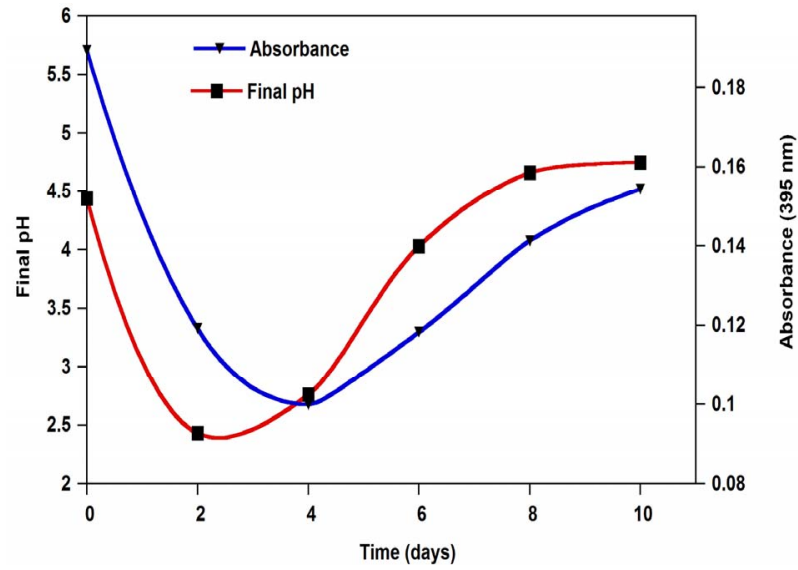

Figure 3. Time course of change in pH and $A_{395} \mathrm{~nm}$ of OMW treated with $A$. niger.
Table 3. Comparative studies of $A$. niger van Tieghem and $P$. chrysosporium degrading OMW.

\begin{tabular}{ccccc}
\hline Cultivation period & \multicolumn{2}{c}{$4^{\text {th }}$ days } & \multicolumn{2}{c}{$\mathbf{9}^{\text {th }}$ days } \\
\hline Strains & A. niger & $\begin{array}{c}\text { P. chryso } \\
\text { sporium }\end{array}$ & A. niger & $\begin{array}{c}\text { P. chryso } \\
\text { sporium }\end{array}$ \\
\hline COD reduction (\%) & 56 & 30 & 63 & 60 \\
PC reduction (\%) & 46 & 38 & 56 & 56 \\
Color reduction (\%) & 64 & 30 & 25 & 50 \\
$\begin{array}{c}\text { Final pH } \\
\begin{array}{c}\text { Generated } \\
\text { biomass (mg) }\end{array}\end{array}$ & 2.5 & 3.16 & 4.66 & 4.24 \\
\hline
\end{tabular}

and $A$. niger in OMW were performed using $250 \mathrm{ml} \mathrm{Er-}$ lenmeyer baffled flasks with $50 \mathrm{ml}$ of OMW based media supplemented with $0.35 \%\left(\mathrm{NH}_{4}\right)_{2} \mathrm{SO}_{4}$ and $0.065 \%$ $\mathrm{KH}_{2} \mathrm{PO}_{4}(\mathrm{w} / \mathrm{v})$. Both strains were able to grow on OMW. As seen in Table 3 the most difference between this strains was, in particular, that $A$. niger had a shorter cultivation periods than $P$. chrysosporium. The results show that $A$. niger was able to reduce all parameters analysed (color $\mathrm{A}_{395}$, phenol content and COD) by at least $50 \%$, after only 4 days of growth. Whereas $P$. chrysosporium needs 9 days of growth to obtain the same results. $A$. niger produced the highest biomass when grown in OMW, and exhibited the best potential for adaptation. P. chrysospo-rium Burdsall M1 produced three ligninolytic enzymes: manganese peroxidases ((MnP), lignin peroxidases (LiP) and phenol oxydase (POX) [10]. The observed difference in the rate of the time courses biodegradation of OMW between $A$. niger and $P$. chrysosporium can possibly be ascribed to in fact that LiP activity reaches a maximum after 6 days of fungal growth, and $\mathrm{MnP}$ and POX activities significantly increase from the $6^{\text {th }}$ day onwards. Whilist tannase activity reaches a maximum during the primary phase of growth [11]. As seen previously, the $\mathrm{pH}$ was one of the mechanisms responsible for discoloration of this effluent. The low $\mathrm{pH}$ (3.16) obtained during $P$. chryso- sporium growth on OMW peaked after 6 days of culture. Whereas the $\mathrm{pH}$ values decreased to 2.5 on the $2^{\text {nd }}$ day of incubation for $A$. niger.

\section{Conclusion}

Aspergillus niger van Tieghem with their capacity to reduce $\mathrm{pH}$ and synthesis tannase offers a new promising approach to bioconversion of phenolic compounds. In fact, the results of the current studies demonstrate that Aspergillus niger van Tieghem is capable of rapidly decolorizing OMW. Removal of phenolic compounds, COD and OD $\left(\mathrm{A}_{395 \mathrm{~nm}}\right)$ was improved by dilution. Discoloration was also improved by the low $\mathrm{pH}$ obtained at the beginning of 
the culture. These results together confer to this fungus a remarkable potential for its application in bioremediation and wastewater treatment, especially in detoxification of phenolic wastes.

\section{REFERENCES}

[1] H. M. Alu'datt, I. Alli, K. Ereifej, M. Alhamad, A. AlTawaha and T. Rababah, "Optimisation, Characterisation and Quantification of Phenolic Compounds in Olive Cake," Food Chemistry, Vol. 123, No. 1, 2010, pp. 117-122. doi:10.1016/j.foodchem.2010.04.011

[2] D. Tabet, M. Saidi, L. Houari, P. Pichat and H. Khalaf, "Fe-Pillared Clay as a Fenton-Type Heterogeneous Catalyst for Cinnamic Acid Degradation,” Journal of Environmental Management, Vol. 80, No. 4, 2006, pp. 342-346. doi:10.1016/i.jenvman.2005.10.003

[3] F. Hanafi, N. Sadif, O. Assobhei and M. Mountadar, "Traitement des Margines par Électrocoagulation Avec des Électrodes Plates en Aluminium," Journal of Water Science, Vol. 22, No. 4, 2009, pp. 473-485.

[4] F. Z. El Hassani, A. Zinedine, M. B. Amraoui, F. Errachidi, S. M. Alaoui, H. Aissam, M. Merzouki and M. Benlemlih, "Characterization of the Harmful Effect of Olive Mill Wastewater on Spearmint," Journal of Hazardous Materials, Vol. 170, No. 2-3, 2009, pp. 779-785. doi:10.1016/j.jhazmat.2009.05.033

[5] F. Hanafi, O. Assobhei and M. Mountadar, "Detoxification and Discoloration of Moroccan Olive Mill Wastewater by Electrocoagulation," Journal of Hazardous Materials, Vol. 174, No. 1-3, 2010, pp. 807-812. doi:10.1016/j.jhazmat.2009.09.124

[6] W.-K. Lafi, B. Shannak, M. Al-Shannag, Z. Al-Anber and M. Al-Hasan, "Treatment of Olive Mill Wastewater by Combined Advanced Oxidation and Biodegradation," Separation and Purification Technology, Vol. 70, No. 2, 2009, pp. 141-146. doi:10.1016/j.seppur.2009.09.008

[7] L. Wu, G. Ge and J. B. Wan, "Biodegradation of Oil Wastewater by Free and Immobilized Yarrowia lipolytica W29," Journal of Environmental Sciences, Vol. 21, No. 2, 2009, pp. 237-242. doi:10.1016/S1001-0742(08)62257-3

[8] I. Sampedro, T. Cajthaml, S. Marinari, M. Petruccioli, S. Grego and A. D’Annibale, "Organic Matter Transformation and Detoxification in Dry Olive Mill Residue by the Saprophytic Fungus Paecilomyces farinosus," Process Biochemistry, Vol. 44, No. 2, 2009, pp. 216-225. doi:10.1016/j.procbio.2008.10.016

[9] N. Asses, L. Ayed, H. Bouallaguia, S. Sayadi and M. Hamdi, "Biodegradation of Different Molecular-Mass Polyphenols Derived from Olive Mill Wastewaters by Geotrichum candidum," International Biodeterioration and Biodegradation, Vol. 63, No. 4, 2009, pp. 407-413.

[10] M. Kissi, M. Mountadar, O. Assobhei, E.Gargiulo, G. Palmieri, P. Giardina and G. Sannia, "Roles of Two WhiteRot Basidiomycete Fungi in Decolorisation and Detoxification of Olive Mill Wastewater," Applied Microbiology and Biotechnology, Vol. 57, No. 1-2, 2001, pp. 221-226.

\section{doi:10.1007/s002530100712}

[11] H. Aissam, F. Errachidi, M. J. Penninckx, M. Merzouki and M. Benlemlih, "Production of Tannase by Aspergillus niger HA37 Growing on Tannic Acid and Olive Mill Waste Waters," Journal of Microbiology and Biotechnology, Vol. 21, No. 4, 2005, pp. 609-614. doi:10.1007/s11274-004-3554-9

[12] APHA, "Standard Methods for the Examination of Water and Wastewater," 20th Edition, American Public Health Association, Washington DC, 1998.

[13] G. Öngen, G. Güngör and B. Kanberoglu, "Decolorisation and Dephenolisation Potential of Selected Aspergillus Section Nigri Strains-Aspergillus tubingensis in Olive Mill Wastewater," World Journal of Microbiology and Biotechnology, Vol. 23, No. 4, 2007, pp. 519-524. doi:10.1007/s11274-006-9254-X

[14] A. Jaouani, S. Sayadi, M. Vanthournhout and M. J. Penninckx, "Potent Fungi for Decolourisation of Olive Mill Wastewaters," Enzyme and Microbial Technology, Vol. 33, No. 6, 2003, pp. 802-809. doi:10.1016/S0141-0229(03)00210-2

[15] D. P. Komilis, E. Karatzas and C. P. Halvadakis, “The Effect of Olive Mill Wastewater on Seed Germination after Various Pretreatment Techniques," Journal of Environmental Management, Vol. 74, No. 4, 2005, pp. 339-348. doi:10.1016/j.jenvman.2004.09.009

[16] R. Capasso, "The Chemistry, Biotechnology and Ecotoxicology of the Polyphenols Naturally Occurring in Vegetable Wastes," Current Topics in Phytochemistry, Vol. 1, 1997, pp. 145-155.

[17] C. Dias-Selassie, T. De-Soyza, M. Rosario, H. Gao and C. Hansch, "Phenol Toxicity in Cells: A Radical Process," Chemico-Biological Interactions, Vol. 113, No. 3, 1998, pp. 175-190. doi:10.1016/S0009-2797(98)00027-1

[18] M. Hamdi, A. Khadir and J. Garcia, “The Use of Aspergillus niger for the Bioconversion of Olive Mill WasteWaters," Applied Microbiology and Biotechnology, Vol. 34, No. 6, 1991, pp. 828-831. doi:10.1007/BF00169359

[19] L. Ayed and M. Hamdi, "Fermentative Discoloration of Olive Mill Wastewater by Lactobacillus plantarum," Process Biochemistry, Vol. 39, No. 1, 2003, pp. 59-65. doi:10.1016/S0032-9592(02)00314-X

[20] F. Hanafi, A. Belaoufi, M. Mountadar and O. Assobhei, "Augmentation of Biodegradability of Olive Mill Wastewater by Electrochemical Pre-Treatment: Effect on Phytotoxicity and Operating Cost," Journal of Hazardous Materials, Vol. 190, No. 1-3, 2011, pp. 94-99. doi:10.1016/j.jhazmat.2011.02.087

[21] K. Fadil, A. Chahlaoui, A. Ouahbi, A. Zaid and R. Borja, "Aerobic Biodegradation and Detoxification of Wastewaters from the Olive Oil Industry,” International Biodeterioration and Biodegradation, Vol. 51, No. 1, 2003, pp. 37-41. doi:10.1016/S0964-8305(02)00073-2

[22] Y. Z. Qin, Z. Anqi, T. David, H. Yu, and Z.-Y. Chen, "Stability of Green Tea Catechins," Journal of Food Chemistry, Vol. 45, No. 12, 1997, pp. 4624-4628. doi:10.1021/jf9706080 
[23] J. A. Field and G. Lettinga, "Treatment and Detoxification of Aqueous Spruce Bark Extracts by Aspergillus ni- ger," Water Science and Technology, Vol. 24, No. 3-4, 1991, pp. 127-137. 